\title{
Intercollegiate Athletics, Institutional Aspirations, and Why Legitimacy is More Compelling than Sustainability
}

\author{
J. Douglas Toma \\ University of Georgia
}

The study by the Knight Commission on Intercollegiate Athletics concludes that Football Bowl Subdivision (FBS) institution presidents are frustrated with some institutions increasingly spending in unsustainable ways on college sports. Between 2004 and 2008 , the median operating budget among the $120 \mathrm{FBS}$ athletics programs increased by $46 \%$, to $\$ 41$ million. The continuing divide between academics and athletics is also a challenge, one that is only exacerbated at some institutions by the perception-and the reality, in certain instances - that provosts and deans are cutting budgets while athletics is awash in money. But the presidents view reform as unrealistic, instead indicating that finding the new revenue needed to continue to compete was their only option.

The Knight study addresses nicely the question of what is occurring. But why are these behaviors happening? Identifying the challenges, such as financial ones, associated with intercollegiate athletics within the FBS is a necessary first step toward reform. But success in reform requires a deeper understanding of why institutions are acting as they are, even when, for some, it is seemingly not in their best financial interests. The question is thus not only whether spending by universities on intercollegiate athletics is sustainable. It is also why some institutions are engaged in such behavior despite such clear signals that it is potentially damaging.

I suggest four reasons why so many universities are spending seemingly beyond their means, arguing that legitimacy gained by institutions through FBS athletics is more compelling than the sustainability that comes with greater restraint.

- Even with significant financial losses, there are considerable intangible strategic advantages associated with prominence in athletics-benefits for institutions that are difficult to monetize.

- The arms race in athletics associated with facilities and compensation has direct parallels with trends on the academic side of institutions as they become more entrepreneurial and commercialized.

- Universities are decidedly more interested than anything in enhancing their prestige — and thus available resources, they perceive — even at the expense of efficiency.

- Those across higher education are unwilling to draw lines between the haves, who can sustain extravagant athletics programs, and the almost-haves and have-nots.

Toma is with the Institute of Higher Education, University of Georgia, Athens, GA. 
I conclude that there is a meaningful, but unrecognized (or perhaps ignored), line between athletics programs that are subsidized by general university funds and those able to generate sufficient resources to be, effectively, independent. The problem is thus not really the sustainability of intercollegiate athletics. It is, instead, whether institutions that must subsidize the enterprise to compete in the FBS are realizing sufficient intangible benefits that advance institutional aspirations toward greater prestige — or have a reasonable prospect of someday doing so- - thus justifying their investment in athletics.

\section{Strategic Advantages}

Resource acquisition through effective external relations is what enables the aspirations of essentially local institutions to national standing. Institutions leverage various intangible benefits connected with FBS-level athletics in securing the resources that serve various broader institutional agendas, including purely academic ones. Concentrating on these uses of intercollegiate athletics in areas such as external affairs requires putting aside important questions related to the mechanics of intercollegiate athletics, with its associated allegations of commercialism and professionalism — and even corruption and exploitation (Toma, 2003).

Having regular mass spectator sports extravaganzas so directly associated with research universities is an accident of history, probably an unfortunate one. But it has been the reality in American higher education for over a century. The question I have asked is not what can we do about it, recognizing that a typical state flagship is as unlikely to scale back its investment in athletics as it would be to retreat from its obsession with advancing in prestige and ranking. Instead, I have found it more productive and satisfying to ask how universities do and can use athletics to advance broader institutional interests, including academic ones.

The essence of external relations is enhancing identification with an institution among constituents. Athletics, when they draw wide attention, as with FBS football, allow a community to relate to something that they perceive to be distinctive, central, and enduring. They thus want to deepen and announce their affiliation (Toma, Hartley, and Dubrow, 2005; Dutton, Dukerich, and Harquail, 1994). Once individuals so identify with what become "their" institutions, successful fund raising and other positive external relations is a natural result. For instance, the connections that Nebraskans develop and continue through the Cornhuskers cause them to become stalwart supporters of not only teams, but also the university. Athletics further provide some-perhaps much, at some universities - of the mystique connected with names and symbols that serve to differentiate institutions from "the pack." The value that comes with these is termed brand equity-the payoff for developing a powerful brand. Through a mix of aura and information, strong brands communicate readily and in enduring ways what the organization wants people to know about it and its products (Toma, Hartley, and Dubrow, 2005; Aaker, 1996).

Organizational identification and brand equity depend upon institutional culture. At larger institutions, prominent athletics are unusually useful in establishing and expressing culture in ways expected by constituents such as students and alumni. In the inexorably linked quest for prestige and appeal for resources that drives strategy, it is insufficient, even at the most prominent research universities, 
to be only perceived as relevant in research, teaching, and service. Institutions must also incorporate the more intimate atmosphere associated with small colleges. Spectator sports enable the expression of the collegiate ideal, albeit imperfectly, that can be otherwise difficult on larger campuses. Within any organization, a distinctive culture develops and becomes established through the repeated expression of symbols, language, narratives, and practices. At large universities, what gives form to culture, making it accessible to people, is predominantly articulated through athletics. These are the colors, logos, and mascots (symbols); songs and slogans (language); stories, legends, and myths (narratives); and rituals and ceremonials (practices) distinctive to an institution (Toma, 2003). Universities tend to have rather standards norms, values, and beliefs - it is the forms culture takes that differentiate them. Just as the most powerful brands tend to be associated with firms having the richest organizational culture, as the culture of an institution strengthens, so does identification with it.

Institutions thus become more appealing and accessible (and even relevant) to those associated with them-particularly external constituents-through the collegiate ideal expressed through spectator sports. Athletics is what many outsiders know and like about an institution, making insiders out of local communities that extend statewide, prompting them to become passionate advocates and supporters. (FBS football may even provide a distraction from activities, such as research in the humanities, which can be difficult to justify as directly relevant to the economic advancement of a state.) Teams provide a locus for the expression of the pride of place that local institutions have long leveraged in garnering support to advance their aspirations toward national prominence. Institutions build on these connections, quite purposefully, in external relations. Games provide a vehicle to bring people onto campus. These might be prospective major donors or key legislators invited to the president's box at the stadium or regular annual fund donors or tuition-paying parents sitting in the stands or watching with interest on television. These are, once again, people who otherwise may not have a direct means of connection to the universities that become a source of pride and even passion for them.

Athletics also provides institutions that are essentially local in their reach with what amounts to a national brand, enhancing the credibility of campuses with few other areas of real national prominence. Not by choice, of course, it is far more likely a university will achieve notice nationally for its football team than for any of its academic functions. Spectator sports (along with geography) are what distinguish otherwise indistinguishable large universities (and otherwise indistinguishable states) on a national level. Institutions that would struggle to make a plausible claim to national standing in any academic field, can do so through athletics. As universities seek resources from increasingly skeptical local sources, such credibility matters, even if it is illogical in its basis.

In drawing on athletics in these ways, institutions are simply using availableand needed - opportunities to their advantage. These uses are intangible in nature, difficult to monetize or otherwise value. What value can an institution, particularly given aspirations to advance in prestige, put upon developing a national name? What is it worth to enhance the appeal and accessibility of a university to local constituents? When considering the matter of expenditures exceeding revenues in athletics, it is important to factor in these intangible benefits for institutions. ${ }^{1}$ 


\section{Parallels with the Broader Institution}

The various arms races that are exacerbating difficulties in balancing athletics budgets without institutions subsidies are parallel with trends within higher education more broadly. There are increasing pressures across the university toward commercialism and professionalism. These are most obvious in athletics, as universities exhibit ever greater creativity in scheduling football games to earn television fees, entering into partnerships with apparel companies and other sponsors, realizing the fund raising possibilities connected with selling choice tickets, and so on. As costs escalate and appropriations dwindle, universities are similarly becoming increasingly entrepreneurial in the academic programs and student amenities they offer. The pressures to depart from traditional academic values are similar to the incentives to elude the amateur ideal in athletics.

The various strategies that universities and colleges employ toward positioning for increased prestige - and thus greater legitimacy - illustrate them acting in an entrepreneurial manner that has never been more characteristic of American higher education. They are responding to the emergence of the neo-liberal ethos within U.S. higher education in the 1980s, emphasizing reliance on markets and attention to internal efficiency amid reduced relative state funding. In framing their case for public support, universities and colleges no longer solely indicate their contributions to advancing the public good, but also more often underscore the return on investment the provide, as with their contributions to local economic development (Zemsky, Wegner, and Massy, 2005). Higher education has increasingly become a commodity, its environment marked by intense competition and rampant consumerism, its purposes ever more connected with individual gain rather than societal good (Marginson, 2006; Slaughter and Rhoades, 2004; Bok, 2002). Traditional academic values continue to matter, but are challenged and at an ever-greater risk of being compromised.

Within this context, higher education institutions, aside from those that eschew any pretense to selectivity, employ a rather predictable set of strategies. They intend these efforts to enhance available resources while increasing prestige, these thought to be mutually reinforcing (Geiger, 2004; Kirp, 2003; Ehrenberg, 2002; Brewer, Gates, and Goldman, 2002). Slaughter and Rhoades (2004) address how universities are intentionally transforming their purposes toward individual gain and away from societal benefit. Acting increasingly as capitalists, institutions are seeking resources in new markets and viewing knowledge as a commodity. They are doing so through expanding management capacity; restructuring faculty work to lower instructional costs (primarily by shifting to temporary labor); subsidizing researchers (who themselves are increasingly focused upon individual gain); and aggressively recruiting accomplished students. Slaughter and Leslie (1997) consider the increasing influence of markets in higher education, including the impact of globalization - and how research funding has become a critical marker of prestige. Zemsky, Wegner, and Massy (2005) note that administration and research have both expanded, the former spreading as on a lattice and the latter steadily ratcheting upward.

Focusing on how universities and colleges are increasingly marketing themselves, as to accomplished students, Kirp (2003) describes institutions as ever more entrepreneurial. They are not only ever more professional in framing messages for 
outsiders, better shaping and managing perceptions, but also launching popular undergraduate majors, emphasizing honors programs, and enhancing study abroad opportunities. Additionally, even institutions not traditionally widely engaged in such activities are seeking strategic advantage through augmenting graduate programs and encouraging faculty research (Kirp, 2003; Geiger, 2004), just as several universities not involved in football are entering the Division I fray. Institutions are meanwhile enhancing campus infrastructure, building impressive student residences, dining commons, fitness centers, and even shopping districts. As these various "arms races" have contributed to escalating discretionary spending, so has the nondiscretionary budget increased, with institutions spending more for basic services such as health benefits, information technology, and deferred maintenance (Zusman, 2005; SCUP, 2005; Lee and Clery, 2004; Dill, 2003; Ehrenberg, 2002). Clotfelter (1996) examines the rapid increases in spending at elite institutions, as for student services, financial aid, and facilities.

Another impact of the quest for prestige is that the price of higher education is increasing, especially at more selective institutions, as recruiting students through tuition discounting, is expensive (Geiger, 2004; Ehrenberg, 2002; McPherson and Schapiro, 1998). There has been a shift in emphasis from need-based toward "merit" student aid at these universities and colleges that is akin to the intense competition across athletics recruiting. As with spending "what it takes" to attract top coaches, among research universities (or aspiring ones), there is also a robust market for faculty thought to be able to conduct research with significant funding or commercial potential (Slaughter and Rhoades, 2004; Geiger, 2004; Kirp, 2003). Geiger (2004) focuses on finances, undergraduates, research, and industry ties at research universities that are increasingly less able to control their own activities, doing less public service and enjoying less government support. He argues that with the ascent of the market in higher education there is a marked and increasing inequality among institutions, with public universities disadvantaged. These same disparities between and among haves, almost-haves, and have-nots are only increasing across intercollegiate athletics. Also as in athletics, there are escalating imbalances within institutions, as units compete with one another and some, like business schools, are better positioned in a market-centered environment (Ehrenberg, 2002). ${ }^{2}$

In response to these pressures, both universities and their athletic programs are increasingly relying on revenues generated at their more agile peripheries. In athletics, among major conference programs, there is the ever-greater presence of-and reliance upon-revenue generated from television, sponsorships, and merchandising. Similarly increasing in prominence are academic programs offered at satellite sites or virtual platforms and addressed to working students studying in professional fields (Slaughter and Rhoades, 2004; Bok, 2002; Zemsky, Wegner, and Massy, 2005; Newman, Couturier, and Scurry, 2004). Institutions have entrepreneurial, as opposed to democratizing, purposes for these programs (Bok, 2002), with students within them primarily interested in credentialing (Collis, 2004; Newman, Couturier, and Scurry, 2004). Managers tend to shape these peripheral academic programs, which are typically staffed by temporary faculty or regular faculty on overload, causing traditional faculty influence to be less pronounced (Bousquet, 2008; Rhoades, 2005; Zemsky, Wegner, and Massy, 2005; Slaughter and Rhoades, 2004). Additionally, institutions have attempted to contain costs (aside from engaging in various arms races) through outsourcing and otherwise 
seeking efficiencies - and other private sector management ideas have permeated higher education (Zemsky, Wegner, and Massy, 2005; Kirp, 2003). Institutions are particularly seeking lower expenses and greater agility through redirecting faculty staffing away from tenure significant positions toward temporary, part-time, and adjunct ones (Bousquet, 2008; Collis, 2004; Lee and Clery, 2004; Zusman, 2005; Gayle, Tewarie, and White, 2003).

Kirp argues that higher education is evolving into just another business, one in which richer institutions (and units and individuals) get richer. Bok (2002), too, examines commercialism, focusing on athletics, scientific research, and academic programs, lamenting what he argues is an obsession over meaningless measures, such as those associated with rankings. But obsessively pursuing and measuring prestige provides a useful surrogate for increasing shareholder value or bottom line profits as an outcome, consistent with a neo-liberal framework. One of several challenges is that it also exacerbates the mission inflation or academic drift that comes with institutions being naturally isomorphic, as with a regional comprehensive university seeking to assume the characteristics of a state flagship (Clark, 1983, Aldersley, 1995; Meyer and Rowan, 1977; DiMaggio and Powell, 1983). In addition, Collis (2004) cautions against mission creep, where "each succeeding tier of the periphery pursues new directions of its own accord" (p. 63), risking expanding everywhere into the periphery and failing to commit sufficient scarce resources to any one venture - the inability to prioritize, in other words. Nevertheless, even the most entrepreneurial institution still must consider measures such as retention, satisfying various accreditation and accountability requirement. Traditional values have hardly been abandoned, even as they are challenged within the neo-liberal university. Athletics may actually be in a more advantageous situation here, as measures such as wins and graduation rates, while still flawed, may be more telling about accomplishments (and even quality) than the reputational rankings. ${ }^{3}$

But despite these commonalities, we continue to focus on the divide between the academics and athletics. Academics and athletics persistently, but needlessly, function as adversaries, rarely working jointly on shared issues or even drawing on the experience of the other to improve practice. Such an illusory divide results from faculty members and academic administrators reducing college sports to stereotypes and favoring an "us versus them" orientation. Even those most interested in these issues can take an overly romantic and thus insufficiently complex view of the realities of both the contemporary university and intercollegiate athletics within it. Arguments of the "we need to just get rid of athletics" type are as unrealistic as those contending "all would be well at the university if the state would support us as they once did." The same is true of most who have written specifically about college sports. Meanwhile, athletic leaders are often insulated from academe, too commonly failing to understand the norms, values, and beliefs that are so important in framing issues. They can fail to appreciate the great distinctions between institution types, to choose just one example. World-renowned research universities and regional teaching-focused institutions are simply portrayed as participants in the FBS, even thought the average SAT scores of entering students may be 300 or 400 points different - the difference between being in the top $10 \%$, as at a top state flagship such as the University of Florida, and bottom $25 \%$ of those taking the test. Sports reporters, who rarely venture from the stadium onto the actual campus, exhibit the same lack of perspective. 
Both sides criticize the other without really acknowledging the contexts in which the other operates-and neither recognizes that trends and issues in both academe and athletics are often more alike than they are different. This fundamental misunderstanding invites problems and marks a lost opportunity. The crises in athletics that can prove so burdensome to university administrations, often in an excruciatingly public manner, are often attributable to a failure in athletics to comprehend the values and mores of academic life. Meanwhile, trends and issues in athletics related to commercialism and professionalism, framed properly, can be illustrative in considering the fundamental questions that academe is asking about maintaining its own values in an environment increasingly marked by external pressures.

\section{Legitimacy and Isomorphism}

Another explanation for why institutions are seemingly willing to take losses in athletics, as necessary, comes from neo-institutional theory. Even as an almosthave or have-not in athletics, modeling behavior-including spending-on the haves lends legitimacy to an institution. DiMaggio and Powell (1983) argue that organizations are more interested in legitimizing themselves through reference to other organizations than seeking efficiency within themselves. In doing so, their access to resources is less likely to be disrupted, reducing turbulence and maintaining stability (Meyer and Rowan, 1977). Institutions thus act to "increase their legitimacy and their survival prospects, independent of the immediate efficacy of the acquired practices and procedures" (Meyer and Rowan, 1977, p. 340). Given a choice between responsible spending and investing toward being perceived as among the leaders in an industry, universities are strongly inclined toward the latter. Accordingly, organizations across types become more homogenous over time, eventually adopting the innovations and practices of those perceived to be atop a field, as these become the prevailing wisdom. If the institutions with the leading athletic programs enter into facilities and compensation arms races, others interested in continuing in the FBS will thus engage in similar behavior to the extent possible.

Such institutional isomorphism is driven both by responding to markets (competitive isomorphism) and competition for political and organizational legitimacy (institutional isomorphism). It is, according to DiMaggio and Powell $(1983,1991)$, coercive, mimetic, or normative. Coercive pressures can come from those upon whom institutions depend for resources (Pfeffer and Salancik, 1978; Pfeffer, 1982) or through formal regulation. In higher education, the need to secure annual state appropriations has a coercive effect on the actions of universities and colleges, as in developing a vision and various strategies to implement it. Boosters can have a similar coercive effect on athletic programs endeavoring to replicate those viewed as being at the top. Mimetic isomorphism is grounded in reducing uncertainty, with imitating market leaders providing reassurance, as there is less risk for universities or colleges in not stepping out from the herd. Consider the risk assumed by the athletic director (or university president) who decides not to pay the large salary or construct the football facility - and compare that with the risks associated with overspending. Normative forces come from those within an organization having been, and continuing to be, acculturated as professionals first as graduate students and later within practitioner networks, thus acquiring a sense of what structures 
and processes are legitimate. ${ }^{4}$ Like faculty members attempting to reshape their current positions and institutions toward being like the leading graduate schools at which they trained, coaches and athletic directors tend to be influenced by their time at the top programs, seeking to bring Oklahoma or Penn State to Louisiana Tech or Buffalo.

Institutions tend not to directly announce their isomorphic tendencies. They also tend to behave in ways other than what they purport or perhaps even want, developing "rationalized myths." These are stories that sometimes have little connection with reality, but reinforce stated institutional purposes toward reassuring both those within an organization, and outsiders. For instance, a small college may frame itself as a traditional liberal arts college both internally and externally, even when the bulk of its activities consist of teaching professional degree courses to part-time, adult students on a satellite campus (Kraatz and Zajac, 1996). Another rationalized myth would be an institution hanging on in the FBS despite the need for considerable subsidies and having a budget that is a small faction of leading institutions, but not wanting to lose being associated with the leading universities and athletic programs nationally. Similarly, institutions rely upon ceremony to signal legitimacy, again both to themselves and outsiders (Jepperson, 1991). It is not necessary for the notions that these ceremonies represent to be proven effective, they only must be believed in (March and Olsen, 1989). Such rationalizations are thus influential in both setting ambitions and later pronouncements about having realized them. Universities and colleges, like other organizations, are not troubled about perceiving and announcing themselves as something other than they actually are.

Another driver toward isomorphism, as reflected in spending, may be that organizational culture tends to limit the solutions that institutions view as legitimate, so they "satisfice," limiting themselves to a few of many possible paths (Simon, 1997). For universities interested in national standing, FBS athletics is among these. Especially when tied to institutional advancement, it is a comfortable strategic direction and an "easy sell" to seemingly all constituents on a campus. Finally, universities are loosely coupled, which means central control over-and even coordination among - units and individuals tends to be weak. Across research universities, those with independent bases of influence and resources, like athletics (but also entrepreneurial faculty), can operate rather autonomously (Meyer and Rowan, 1977; Scott, 2003, 2001). Unless those in athletics are interested in cost reduction, it is unlikely that central administrations can impose it - and given the pull of legitimacy through isomorphism, presidents are probably no inclined to push here.

\section{Drawing Lines in U.S. Higher Education}

Noting that university presidents are concerned about the sustainability of spending on college sports requires a significant qualification-that there is no real crisis among the relative few haves among athletics programs. These haves are generating sufficient revenue to manage without subsidies from their institutions, even while spending aggressively. But few are willing to draw-or simply articulate-such lines, whether in athletics or elsewhere in higher education. Everyone, regardless of resources that can be a fraction of leading institutions, can simply claim a position within the top classification, whether in the FBS or as a research university. 
For instance, the University of Michigan, the University of WisconsinMilwaukee, and the University of Wyoming would all label themselves-and be classified, as by Carnegie-as research universities. But Michigan has 20 times more in both research expenditures and endowment assets than UWM and Wyoming, ranked 200th in these respective areas. Similarly, among the roughly 330 programs in Division I intercollegiate athletics, Ohio State generates and spends about $\$ 90$ million annually (using 2006 data). The smallest programs in the division, institutions such as Nicholls State, Maryland-Eastern Shore, and North Carolina-Asheville, have yearly budgets about three percent of that. Conference television contracts are similar in proportion. Beginning in 2009, the Southeastern Conference (SEC) began receiving $\$ 55$ million from CBS and $\$ 150$ million annually from ESPN-ABC through broadcast rights contracts- $\$ 205$ million in total. Splitting these revenues among the 12 athletics programs in the conference accounts for about $\$ 17$ million of their respective budgets. In contrast to the SEC, the Mountain West Conference television deal is closer to \$12 million per year, while the Western Athletic Conference contract is closer to $\$ 4$ million and the Mid-American Conference is about $\$ 1.5$ million. ${ }^{5}$ Bowl revenue is also apportioned to FBS conferences along these lines. ${ }^{6}$

Even among the 66 programs in the six leading conferences (and Notre Dame) that comprise the Bowl Coalition Series (BCS) - those with the most modest budgets, such as Cincinnati, are one-third that of Ohio State. In the Southeastern Conference, Florida and Georgia, in the top ten or so nationally, have budgets that are more than twice those of Mississippi State and Vanderbilt. The same is the case with research and endowments. Virginia Tech was 50th in research funding at \$290 million and the University of California-San Francisco was 50th in endowment at $\$ 1.2$ billion-both about one-third of Michigan. Even within the Association of American Universities (AAU), members such as Kansas and Nebraska generate revenues from tuition, appropriations, research, and endowments sufficiently different from Wisconsin and Berkeley—not to mention Stanford and Yale- that it is probably not all that useful to put them in the same category for the purposes of comparison.

A clear line between the have-nots and others is "guarantee" games in football-something to which there is not an obvious comparison elsewhere in higher education. These involve a more prominent program hosting at a team from one of the smaller FBS institutions or from the former Division I-AA (the Football Championship Subdivision or FCS). The more modest program earns a payment for visiting, with more attractive guarantee games involving FBS teams now attracting in the \$1 million range, with FBS games generating about one-third of that. And a market has developed around the smaller programs shopping themselves among the larger ones, driving up prices. These games are essential to less wealthy FBS programs and to FCS teams, given their budgets closer are \$20 million (and sometimes more like $\$ 10$ million), and the limits to their ability to generate revenue otherwise, as from television. So, Arkansas State played at Nebraska, Iowa, and Louisville in 2009 and FCS member Charleston Southern visited Florida and South Florida. Meanwhile, home games in larger stadiums can generate upwards of $\$ 7$ million, when factoring in everything, so adding a seventh home game is also important to the bottom line at the haves, appetites for revenue seemingly being insatiable in college sports, as in higher education generally. 
But the primary line between the haves, almost-haves, and have-nots is in program subsidies. Georgia, which receives only a negligible institutional subsidy, generated about $\$ 75$ million in revenue in 2006 , with a surplus of about $\$ 25$ million and nearly $\$ 60$ million in reserves at the beginning of 2009. In addition to SEC and local television revenue and other sources such as sponsorships, Georgia generates about \$18 million in football ticket sales each year and another \$4 million in revenue from suites - and \$26 million in donations to preserve the right of donors to purchase tickets. (Over one-third of total annual fund raising at UGA of roughly $\$ 100$ million is in athletics.) It recently completed the construction of a $\$ 35$ million basketball and gymnastics practice facility and broke ground on a $\$ 40$ million football building addition in 2009.

Rutgers, an almost-have, has a budget closer to $\$ 40$ million-around 50th among institutions nationally-raising $\$ 4$ million in athletic donations. But Rutgers athletics receives a nearly $\$ 15$ million in direct and indirect support from the university, as well as over $\$ 5$ million in student fees. It spends about the $\$ 12$ million annually that Georgia does on football. Representative of the have-nots, Eastern Michigan has a \$20 million annual budget, generated through \$7 million from student fees, \$2 million from state funds, and \$8 million in institution support, both direct and indirect. (Direct support is in the form of tuition waivers or actual transfers, while indirect support involves the use of facilities and staff from the universities.) EMU generates minimal funds through tickets sales, contributions from individuals, conference distributions, and other sources. It spends about $\$ 4$ million on football annually.

Tables 1 and 2 portray these differences in FBS public institutions in six states (Georgia, Michigan, Ohio, New Jersey, North Carolina, Virginia). The lines between the haves, almost-haves, and have-nots are clear. Not only is athletics revenue among the Mid-American Conference programs at the bottom of the table one-quarter to one-sixth of top programs such as Ohio State, Michigan, Georgia, Virginia, and Michigan State, but football spending is also in the one-third range. Most of the budget for these have-not programs comes from institutional transfers or student fees and each takes a significant loss on football.

The issue of subsidies has become more pronounced, given cuts in institutional budgets over the past two years. The University of Georgia experienced cuts in its state budget of about $\$ 500$ million of eight percent in 2008 and ten percent in 2009. The institution imposed on employees six days of state-mandated furloughs in 2009, constituting a three percent temporary pay cut, but has resisted layoffs. At institutions that subsidize athletics, such cuts would occur there also. At Stanford, for instance, $40 \%$ of the yearly athletic budget of around $\$ 72$ million is generated from a combination of endowed funds and almost $\$ 10$ million in transfers from the institution. Stanford athletics also draws on $\$ 12$ million in expendable gifts annually. With endowments declining steeply beginning last year and corresponding cuts in institutional spending, Stanford has been forced to make significant reductions in athletics spending, including eliminating positions, with $\$ 8$ million in cuts anticipated in 2010 and $2011 .^{7}$

As with television contracts, such budget cuts will only increase the separation between the haves and everyone else in intercollegiate athletics. There has been a similar trend across higher education, with the separation between private and public higher education increasing (Geiger, 2004). Only the steep decline in 


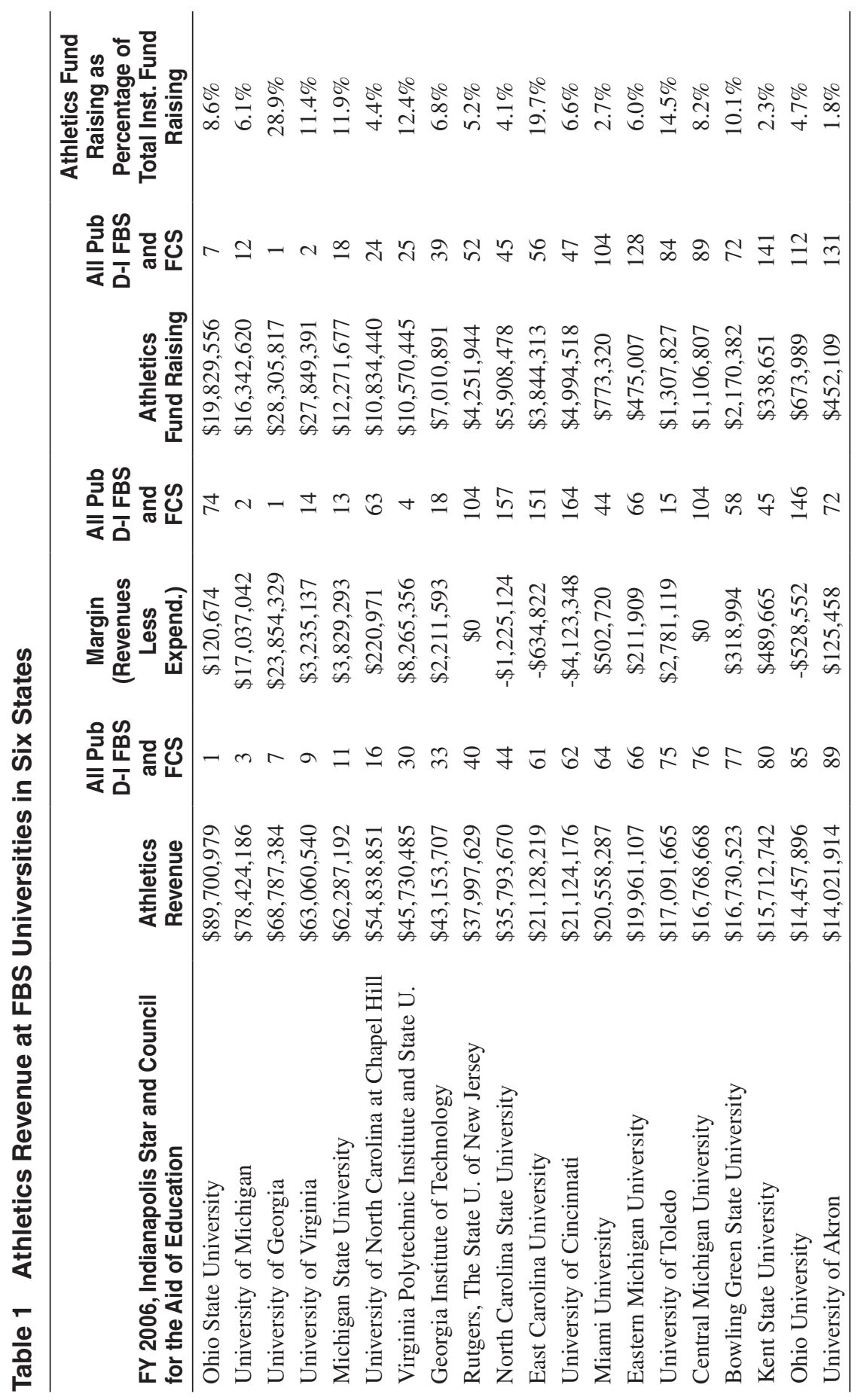




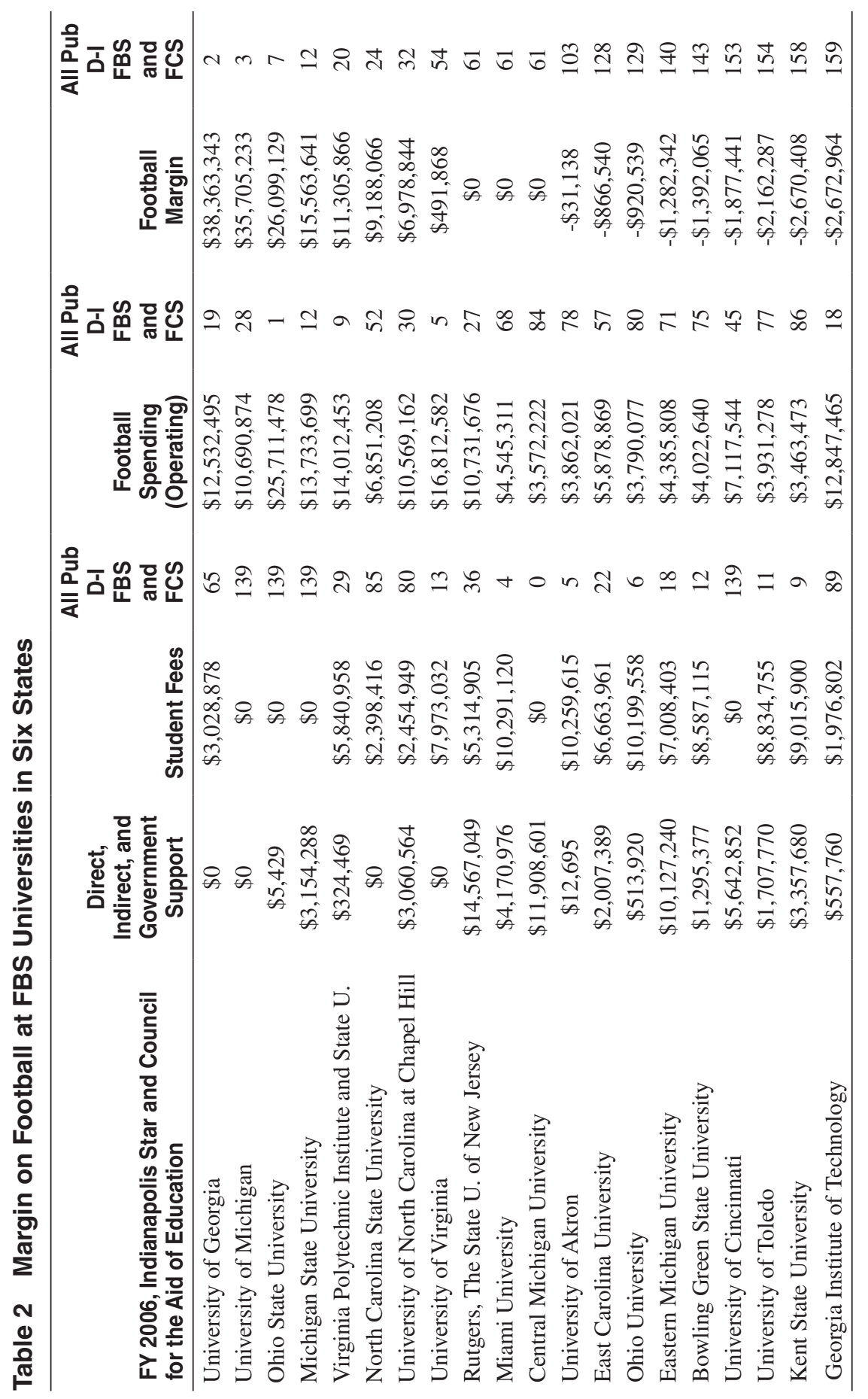


endowments in 2008 and 2009, which have been similar-if not worse-than cuts in state appropriations, have slowed the trend. But in athletics, leading programs, like Georgia, are little affected by the global economic crisis_-and are increasing the distance between themselves and everyone else.

None of this is to say that universities or athletics programs with lesser resources cannot compete favorably. It is simply to suggest that those at the top have significant advantages. They are likely to prevail more often than not in the most intense competitions, as for the most desirable students, elite researchers, impressive donations (and perhaps even research funding)_ as well as on the field. The national champions in football since 1998-Florida, Louisiana State, Texas, Southern California, Ohio State, Miami, Oklahoma, Florida State, and Tennessee-are in the top 25 in resources devoted to athletics (with the exception of Miami). So, there are lines in college sports apart from the FBS, or even the BCS, versus others. The 20 or 30 programs and institutions able to generate the most revenue are racing ahead, with another group of 30 or 40 doing what they can to keep pace, but with little prospect of actually doing so. Several others are simply content to make a plausible case that they live in the same neighborhood, albeit in a much smaller house. The same is true among research universities in roughly similar proportions.

\section{Concluding Thoughts}

Why does Eastern Michigan University subsidize nearly its entire \$20 million athletics budget? There have to be more appropriate purposes for these funds within a higher education institution, right? There is a student development rationale for sports such as volleyball and swimming, but hardly for the football and men's basketball at the Division I level that consume so many resources. Instead, the university is investing as it does elsewhere in external relations, building the image and extending the reach of the institution. Universities such as EMU justify taking annual losses on intercollegiate athletics given the hope that they will someday be able to benefit from the advantages associated with athletics prominence. These include the ability to more readily connect with alumni and potential donors; having a more concrete national identity and higher profile among local constituents; and fitting more neatly within the popular conception of a major American university.

In response to such concerns, Georgia State, Texas-San Antonio, and UNCCharlotte are all launching Division I-AA football programs. Having constructed on-campus housing, dining, and fitness facilities, each perceives football as the missing piece in being considered a "real" university by the accomplished students they are attempting to enroll to enhance their U.S. News rankings. While there are occasional success stories, such as the emergence of South Florida over the past decade as a prominent football program, new teams are likely to struggle financially for several years. But the opportunity to be more like the universities that these institutions aspire to become-state flagships such as Georgia Tech, Texas A\&M, and N.C. State - is worth it, seemingly regardless of the expense. Ultimately, Eastern Michigan is unlikely to ever break away from annual subsidies for athletics. It is purchasing membership in the group of 120 or so institutions in the top division in college sports, which is important not only strategically, but also for its psyche. Its pursuit of research funding and graduate programs may be similar-and probably even more expensive. 
Given the "aspirational" ends institutions intend them to serve, I am hesitant to criticize subsidies for athletics. Part of what makes American higher education so dynamic is that universities and colleges are so ambitious-everyone is constantly seeking that next level of stature. There is nothing quite so challenging for an institution as attempting to keep pace when market leaders are moving ahead so rapidly. But is opting out really an option for EMU? Can its president realistically say that the institution is simply going to consolidate its gains and move away from attempting to ever compete, including symbolically on the field, with the neighboring University of Michigan? ${ }^{8}$

\section{Notes}

1. I develop these arguments in Football U.: Spectator Sports in the Life of the American University (2003). I also include them in a chapter with Dennis Kramer to introduce an edited volume titled: The Uses of Intercollegiate Athletics: Opportunities and Challenges in Positioning the University (2009).

2. In addition to the standard works on the neo-liberal university, there is a robust literature critical of contemporary higher education. In just the past few years, Lewis (2006) writes of the lack of coherence in the curriculum, faculty disconnectedness from students, and coddled and infantilized students at Harvard; Bok (2007) and Kronman (2007) discuss what students are not learning (including the meaning of life, the latter argues); Giroux (2007) and Newfield (2008) focus on the influence of conservatives in, respectively, chilling critical thought and suppressing democratizing impulses in higher education; Golden (2007) and Schmidt (2007) consider the advantages affluent applicants have in elite admissions; Rhode (2006) addresses the negative impact of the pursuit of status on the pursuit of knowledge (as do, more generally, Hersh and Merrow (2006)); Washburn (2006) discusses negative corporate influences; and Bousquet (2008) explores faculty as disposable workers within the low-wage sphere of the service economy. Finally, Burgan (2006) writes of decline of faculty influence and its impact.

3. I illustrate these trends in the Toma (2008) paper on which I draw the text above, as well as in my 2010 book, Building Organizational Capacity: Strategic Management in Higher Education. The two paragraphs following are from the introduction to my edited monograph cowritten with Dennis Kramer.

4. Organizational institutionalism is the dominant theory in organizations and management, with citations to Meyer and Rowen (1977), DiMaggio and Powell (1983), and Pfeffer and Salancik (1978) related to institutional theory and resource dependency increasing over the past decade (Greenwood, et al., 2008). Subsequent research has only made institutionalism more complex and applicable as a theory, as with expanding consideration of questions of isomorphism and legitimacy into areas such as institutional entrepreneurship (active change within organizations) and institutional logics (influence of broader belief systems, such as capitalism) (Leca, Battilana, and Boxenbaum, 2006; Friedland and Alford, 1991).

5. These differences are likely to accelerate. The new $\$ 205$ million annual SEC contract is a significant increase, for instance. In 2007, the conference shared \$127 million among its 12 members, an increase from $\$ 16$ million in 1990. In addition, each SEC program can negotiate its own local broadcasting package, with Florida and Georgia receiving in the neighborhood of $\$ 10$ million yearly (Toma, 2009). These possibilities are severely limited for other programs, even some in smaller markets in the SEC. In addition, there is the revenue the conferences receive from bowl games, which can be as high as $\$ 50$ million in the SEC. Smaller programs and conferences earn a small fraction of these amounts-somewhere between a fifth and a tenth. Revenue from 
NCAA distributions associated with its annual men's basketball tournament is also generated through a formula that favors larger conferences.

6. For instance, BCS games generate $\$ 17$ million per participant, which is pooled by conferences and allocated to members. The next tier of lucrative bowls (including the Cotton, Capital One, Outback, Gator) are also sponsored by corporations and essentially reserved from teams from the six largest conferences. There are 25 or so bowls other than the BCS games, many available to teams from smaller conferences, but with payouts in the $\$ 1$ million per team range. Programs often take a loss on these games, as they must cover certain travel expenses and purchase a significant block of tickets that they may not be able to resell. Even the best-case scenario for smaller programs is thus not particularly appealing. Michael Oriard (2008) contends that occasional forays into the BCS by non-BCS institutions is misleading: "The occasional upset and rogue title contender shouldn't obscure the fact that mostly, the same schools contend for the championship each year. .. These outliers break through one at a time, then promptly lose their coach to a major BCS power temporarily fallen on hard times (or lose their star quarterback to the NFL) and once again take their proper places in the food chain." The only potential leverage the smaller programs have is in the courts or through federal legislation. The present bowl system is questionable under antitrust law, which applies to intercollegiate sports and weighs procompetitive benefits against anticompetitive effects when looking at monopolistic practices. If challenged in court by a class of perceived Division I FBS outsiders, as is regularly threatened, the question would become whether the anticompetitive effects of the BCS system within the FBS, given its relative exclusivity, outweigh the procompetitive impacts. Legislation could have the same impact of applying the antitrust laws to the bowl system, a prospect most recently raised by Senator Hatch after an undefeated Utah team was denied an appearance in the national championship game in 2009. So far, the BCS has dodged legal or legislative trouble by opening access to the BCS to a team from the smaller conferences and making an annual transfer payment.

7. Mike Cross has been tracking such cuts across U.S. intercollegiate athletics at www.ulitmatesportsinsider.com.

8. What might change the situation - and not necessarily for the better-is the potential loss by college football of its tax-exempt status. For over a century, the sport has been associated with the corporate sponsorships, races to build impressive facilities that go well beyond function toward opulence, salaries for coaches far in excess of others on campus, etc. that define contemporary college football. But these commercial and professional traits have become increasingly conspicuous, with major donations to the athletic foundation required for access to good seats and television asserting ever more influence over scheduling. Such attributes connect college football as much with commerce as with higher education - perhaps more so. The NCAA and its member institutions have, by necessity over time, exhibited great skill in framing football as amateur in character. Maintaining a plausible connection to the accepted missions of universities, including developing character in students through extracurricular activities, enables the enterprise itself. It is what allows college football, even with its commercial and professional nature, to fit within the university - and thus have a value to society such that it is exempt from federal and local taxation. Were football programs to be taxed, already stretched budgets for many programs would perhaps snap. In addition to having to pay taxes, the inability to any longer make plausible claims to amateurism might raise the possibility of players being able to collectively bargain (as graduate student teaching assistants at public institutions can). It might also encourage the elimination of the tax breaks that drive private donations to athletic programs, including for luxury seating. There would be no choice but to contract athletics spending, including at the wealthiest programs, and smaller budget programs might be forced into more of a Division II or III model. As commercial activity increases and fund raising becomes ever more important across institutions, particularly research universities, such a precedent could prove to be dangerous outside of college sports. Like in college football, is the ability of the research university to claim "amateur" status compromised by its increasingly commercial character? 


\section{References}

Aaker, D.A. (1996). Building Strong Brands. New York: Free Press.

Aldersley, S.F. (1995). "Upward drift" is alive and well: Research/doctoral model still attractive to institutions, Change (pp. 51-56). Sep.-Oct.

Bok, D.C. (2002). Universities in the Marketplace: The Commercialization of Higher Education. Princeton, NJ: Princeton University Press.

Bok, D.C. (2007). Our Underachieving Colleges: A Candid Look at How Much Students Learn and Why They Should Be Learning More. Princeton: Princeton University Press.

Bousquet, M. (2008). How the University Works: Higher Education and the Low-Wage Nation. New York: New York University Press.

Brewer, D., Gates, S.M., \& Goldman, C.A. (2002). In Pursuit of Prestige: Strategy and Competition in U.S. Higher Education. New Brunswick: Transaction Press.

Burgan, M. (2006). What Ever Happened to the Faculty? Drift and Decision in Higher Education. Baltimore, MD: Johns Hopkins University Press.

Clark, B.R. (1983). The Higher Education System: Academic Organization in Cross-National Perspective. Berkeley: University of California Press.

Clotfelter, C. (1996). Buying the Best: Cost Escalation in Elite Higher Education. Princeton, NJ: Princeton University Press.

Collis, D. (2004). The paradox of scope: A challenge to the governance of higher education. In W. G. Tierney (Ed.), Competing Conceptions of Academic Governance: Navigating the Perfect Storm (pp. 33-76). Batlimore: Johns Hopkins University Press.

Dill, D.D. (2003). Allowing the market to rule: The case of the United States. Higher Education Quarterly, 57(2), 136-157.

DiMaggio, P.J., \& Powell, W.W. (1983). The iron cage revisited: Institutional isomorphism and collective rationality in organizational fields. American Sociological Review, 48, 147-160.

DiMaggio, P.J., \& Powell, W.W. (1991). Introduction. In W. W. Powell and P. J. DiMaggio, The New Institutionalism in Organizational Analysis (pp. 1-38). Chicago: University of Chicago Press.

Dutton, J.E., Dukerich, J.M., \& Harquail, C.V. (1994). Organizational images and member identification. Administrative Science Quarterly, 39, 239-263.

Ehrenberg, R. (2002). Tuition Rising: Why College Costs So Much. Cambridge, MA: Harvard University Press.

Friedland, R., \& Alford, R.R. (1991). Bringing society back in: Symbols, practices, and institutional contradictions. In W. W. Powell and P. J. DiMaggio, The New Institutionalism in Organizational Analysis (pp. 232-266). Chicago: University of Chicago Press.

Gayle, D.J., Tewarie, B., \& White, A.Q., Jr. (2003). Governance in the twenty-first century university: Approaches to effective leadership and strategic management. ASHE-ERIC Higher Education Report, (30)1. San Francisco: Jossey-Bass.

Geiger, R. (2004). Knowledge and Money: Research Universities and the Paradox of the Marketplace. Stanford, CA: Stanford University Press.

Giroux, H.A. (2007). The University in Chains: Confronting the Military-IndustrialAcademic Complex. Boulder, CO: Paradigm Publishers.

Golden, D. (2007). The Price of Admission: How America's Ruling Class Buys Its Way into Elite Colleges - and Who Gets Left Outside the Gates. New York: Three Rivers Press.

Greenwood, R., Oliver, C., Sahlin, K., \& Suddaby, R. (2008). Introduction. In R. Greenwood, C. Oliver, K. Sahlin, \& R. Suddaby (Eds.), The SAGE Handbook of Organizational Institutionalism (pp. 1-46). Thousand Oaks, CA: SAGE.

Hersh, R.H., \& Merrow, J. (2006). Declining by Degrees: Higher Education at Risk. New York: Palgrave Macmillan.

Jepperson, R.L. (1991). Institutions, institutional effects, and institutionalism. In P.J. DiMaggio, P. J. \& Powell, W. W., eds., The New Institutionalism in Organizational Analysis (pp. 143-163). Chicago: University of Chicago Press. 
Kirp, D. (2003). Shakespeare, Einstein, and the Bottom Line: The Marketing of Higher Education. Cambridge, MA: Harvard University Press.

Kraatz, M.S., \& Zajac, E.J. (1996). Exploring the limits of the new institutionalism: The causes and consequences of illegitimate organizational change. American Sociological Review, 61(5), 812-836.

Kronman, A.T. (2007). Education's End: Why Our Colleges and Universities Have Given Up on the Meaning of Life. New Haven: Yale University Press.

Leca, B., Battilana, J., \& Boxenbaum, E. (2006). Taking stock of institutional entrepreneurship: What do we know? Where do we go? Paper presented at the Academy of Management Meeting, Atlanta, GA.

Lee, J., \& Clery, S. (2004). Key trends in higher education. American Academic, 1(1), 21-36.

Lewis, H.R. (2006). Excellence Without a Soul: How a Great University Forgot Education. New York: Public Affairs.

March, J.G., \& Olsen, J.P. (1989). Rediscovering Institutions: The Organizational Basis of Politics. New York: The Free Press.

Marginson, S. (2006). Enabling democratic education in the neoliberal age. Educational Theory, 56(2), 205-219.

McPherson, M.S., \& Schapiro, M.O. (1998). The Student Aid Game: Meeting Need and Rewarding Talent. Princeton: Princeton University Press.

Meyer, J.W., \& Rowan, B. (1977). Institutionalized organizations: Formal structure as myth and ceremony. American Journal of Sociology, 83(2), 340-363.

Newfield, C. (2008). Unmaking the Public University: The Forty-Year Assault on the Middle Class. Cambridge: Harvard University Press.

Newman, F., Couturier, L., \& Scurry, J. (2004). The Future of Higher Education: Rhetoric, Reality, and the Risks of the Marketplace. San Francisco: Jossey Bass.

Oriard, M. "Bowling for dollars: Why college football is more cutthroat and competitive than the NFL." Slate, November 6, 2008. www.slate.com.

Pfeffer, J. (1982). Organizations and Organization Theory. Marshfield, MA: Pitman.

Pfeffer, J., \& Salancik, G.R. (1978). The External Control of Organizations: A Resource Dependence Perspective. New York: Harper and Row.

Rhoades, G. (2005). Capitalism, academic style, and shared governance. Academe, 91(3), 38-42.

Rhode, D. (2006). In Pursuit of Knowledge: Scholars, Status, and Academic Culture. Stanford: Stanford University Press.

Schmidt, P. (2007). Color and Money: How Rich White Kids Are Winning the War over College Affirmative Action. New York: Palgrave Macmillan.

Scott, R.W. (2001). Institutions and Organizations (2nd ed.). Thousand Oaks, CA: Sage Publications.

Scott, W.R. (2003). Organizations: Rational, Natural and Open Systems (5th ed.). New York: Prentice Hall.

Simon, H. (1997). Administrative Behavior: A Study of Decision-Making Processes in Administrative Organizations (4th ed.). New York: The Free Press.

Slaughter, S., \& Rhoades, G. (2004). Academic Capitalism and the New Economy. Baltimore: Johns Hopkins University Press.

Slaughter, S., \& Leslie, L.L. (1997). Academic Capitalism: Power, Politics and the Entrepreneurial University. Baltimore: Johns Hopkins University Press.

Society for College and University Planning. (2005). Trends in higher education. Ann Arbor, Michigan: SCUP.

Toma, J.D. (2010). Building Organizational Capacity: Strategic Management in Higher Education. Baltimore: Johns Hopkins University Press.

Toma, J.D. (2009). The business of intercollegiate athletics. In D. Siegel \& J. Knapp (Eds.), The Business of Higher Education (pp. 179-216). Santa Barbara, CA: Praeger.

Toma, J.D. (2008). Positioning for prestige in higher education: Case studies of aspirations and strategies at four public institutions toward "getting to the next level." Paper 
presented at the Association for the Study of Higher Education Annual Meeting, Louisville, Kentucky.

Toma, J.D. (2003). Football U.: Spectator Sports in the Life of the American University. Ann Arbor, MI: University of Michigan Press.

Toma, J.D., \& Kramer, D. (2009). The uses of intercollegiate athletics. In J.D. Toma \& D. Kramer (Eds.), The Uses of Intercollegiate Athletics: Opportunities and Challenges in Positioning the University (pp. 1-9). San Francisco: Jossey-Bass.

Toma, J.D., Hartley, M., \& Dubrow, G. (2005). The Uses of Institutional Culture: Strengthening Identification and Building Brand Equity in Higher Education. ASHE Higher Education Reports, 31(3). San Francisco: Jossey-Bass.

Washburn, J. (2006). University, Inc.: The Corporate Corruption of American Higher Education. New York: Basic Books.

Zemsky, R., Wegner, G.R., \& Massy, W.F. (2005). Remaking The American University: Market-Smart And Mission-Centered. New Brunswick, NJ: Rutgers University Press.

Zusman, A. (2005). Challenges facing higher education in the twenty-first century. In P.G. Altbach, R.O. Berdahl, \& P.J. Gumport (Eds.), American Higher Education in the Twenty-First Century: Social, Political, and Economic Challenges (pp. 115-160). Baltimore: Johns Hopkins University Press. 